\title{
Factors Associated with the Acceptance of a Novel Integrated Care Service by Community-Dwelling Elderly in Chongqing, China
}

\author{
Huang Huanhuan \\ Chen Zhiyu \\ Chongqing Medical University First Affiliated Hospital \\ Xiao Mingzhao \\ Chongqing Medical University First Affiliated Hospital \\ Xiao Ling \\ Chongqing Medical University First Affiliated Hospital \\ Chen Mei \\ Bishan Hospital \\ Jia Wenbi \\ Chongqing Medical University First Affiliated Hospital \\ Zhao Qinghua ( $804583740 @ q q . c o m$ )
}

Chongqing Medical University First Affiliated Hospital https://orcid.org/0000-0001-5957-5560

\section{Research article}

Keywords: community-dwelling elderly, Medical Union, Anderson's health behavioral model, health care services

Posted Date: September 26th, 2019

DOl: https://doi.org/10.21203/rs.2.15198/v1

License: (c) (7) This work is licensed under a Creative Commons Attribution 4.0 International License. Read Full License 


\section{Abstract}

Background: Medical Union is a novel model of integrated care services. At present, the Chinese government encourages the development of health care services for aged people provided by Medical Union which may help make effective use of limited medical resources in China.

Purpose: This study aims at examining the prevalence of and associated factors affecting the acceptance of a novel integrated care service by community-dwelling elderly.

Methods: We extracted raw data generated from 1,180 community residents over 60 years old and performed binary logistic regression analyses to predict odds of the acceptance in Chongqing, China. Using Anderson's health behavioral model, we examined three groups of predictive factors: (1) predisposing factors (e.g. social demographic information), (2) enabling factors (e.g. health insurance status), (3) need factors (e.g. health status).

Results: The application of this novel integrated care service was explained better by enabling factors than other predictive factors. In the best explanatory model (model 3), one predisposing factor (degree of education), one enabling factor (insurance type), and five need factors (self-reported health status, hypertension, diabetes, dyslipidemia, and disability) were variables considered as the significant factors affecting the acceptance of the novel integrated care service by community-dwelling elderly in Chongqing, china.

Conclusion: This study provides an empirical understanding of the equity of the access to a novel integrated care service for older adults who live in communities. Our findings advocate that primary health institutions should play an important role in health education. Advanced policies are needed to protect physically and economically vulnerable groups.

\section{Background}

Accompanied with the rapid growth of economy, China has developed into a country with an ageing population. According to the latest data from China's National Bureau of Statistics in 2019, the number of people aged 60 years and over in China has being reaching 249 million which accounts for $17.9 \%$ of the total population. It is estimated that by 2020 , the aged population in China will exceed 250 million, accounting for nearly $20 \%$ of the total population ${ }^{[1]}$. In the meantime, Chinese families have become smaller due to the one-child policy, population migration plan, as well as a living style separating the older parents and their children. The family structure is showing a trend of miniaturization and centralization ${ }^{[2]}$. Above all, the wave of ageing has been an unneglectable issue associated with social welfare in China, especially at this very point of society transformation and robust growth of economy ${ }^{[3]}$.

In response to the critical ageing problem and the enhanced diversity of social healthcare services, "integrated care" is becoming a common policy for healthcare services in various countries ${ }^{[4]}$. In the context of the ongoing medical reforms, big cities in China and Chinese scholars focus on the exploration of vertical integration of health care ${ }^{[5]}$, of which the representative model is "Medical Consortium", also known as "Hospital Groups" [6] The Medical Consortium is a vertical type of general medical services, usually involving a widely appreciated tertiary hospital and several secondary hospitals or community health centers; it improves patients' responses to treatments through the cooperation between institutions at different levels ${ }^{[7]}$. From a macroscopic perspective, this is a top-level design of resource integration which can alleviate the structural contradictions of uneven distribution of medical resources and low rate of resource utilization. Meanwhile, via the division of labor and cooperation among various institutions, the public can be provided with comprehensive and continuous medical and health care services. From a microscopic perspective, this is also a strategy for different institutions to combine their advantages, compete with each other in a positive way, and reinforce their influence ${ }^{[8]}$. In 2017, the State Council of China issued a policy, proposing to build and develop Medical Consortiums in order to strengthen the combination of health services and pension services and speed up the integrated service for disease diagnosis, treatment, rehabilitation, and long-term care ${ }^{[9]}$. Up to now, $94.7 \%$ of cities above the municipal level in China have their own Medical Consortiums, and the construction of Medical Consortium has relatively matured ${ }^{[10]}$.

At present, some scholars have investigated the acceptance of the health care by elderly in China ${ }^{[11-13]}$, but none of them targets on the integrated care service of Medical Consortium. Therefore, we decided to analyze the factors related to the acceptability of 
this novel medical service among community-dwelling elderly using a mature theoretical model.

\section{Methods}

\subsection{Ethics statement}

This study was part of a provincial-level project in China. It was a cross-sectional study with a large sample size and approved by the Ethics Committee of the First Affiliated Hospital of Chongqing Medical University (No.:2019-105). Each participant was informed by a written consent to assure their rights to know. Personal information was completely confidential and participants were tracked anonymously according to their assigned unique number.

\subsection{Data source}

The data used in this paper originated from the questionnaire survey of "Construction of personalized pension service model based on Medical Consortium", a key project from Chongqing Science and Technology Committee. The questionnaire survey was conducted from December 2018 to June 2019. It was done in Chongqing which consisted of 26 districts, 8 ordinary counties, and 4 autonomous counties. Convenience sampling was used to select participants and the survey was mainly performed in the form of face-to-face interviews. Our target population was elderly people over 60 years old living in communities in Chongqing. In total, 1,299 questionnaires were collected of which 1,180 were valid, with an effective recovery rate of $90.84 \%$. A flow chart of participant recruitment and eligibility screening is provided in Figure 1.

\section{3 variable selection}

Anderson's model, also known as behavior model of health services use (BMHSU), was first proposed in 1968 by medical sociology and health services researcher Ronald $m$ Andersen ${ }^{[14]}$. Being tested by a large number of empirical studies, Anderson model has been gradually improved after many revisions ${ }^{[15]}$ and widely used in the field of medical and health service to analyze the influencing factors of medical service behavior for individuals ${ }^{[16,17]}$.

The dependent variable (a dichotomous variable) of this study was the community elderly's willingness to accept a novel integrated care service supplied by Medical Consortium. Participants who were willing to accept it were coded as "0", participants who refused to accept it were coded as " 1 ". Other factors that might affect the acceptance were considered as independent variables which had been identified by other researchers ${ }^{[18]}$. And BMHSU included 3 groups of factors shown as follows:

Predisposing Factors The predisposing factors are the demographic and sociological characteristics of the tendency to utilize or accept medical and health services but not directly related to the behaviors ${ }^{[19]}$. Five variables such as age, gender, education level, marital status, and residential area were assessed in this study. Among them, age was a numerical variable and displayed in the form of mean and standard deviation ( $\overline{\mathrm{x}} \pm \mathrm{SD}$ ). The gender was coded as " 1 " for males and " 0 " for females. Based on the nine-year compulsory education policy in China ${ }^{[20]}$, the education level was labelled as 4 to 0 , i.e. illiteracy (4), elementary school (3), middle school (2), high school (1), and college (0). In terms of marital status, "1" stood for no spouse which consisted of divorced, widowed, and single participants while " 0 " represented married. With regard to the residential areas which included counties and districts, the former was assigned a value of "1" and the latter was "0" according to the present administrative division [21].

Enabling Factors The enabling factors refer to the family's ability to obtain medical and health services and are indirect influencing factors for medical and health services. This category mainly consists of residents' annual income and medical insurance resources ${ }^{[22]}$. Based on the average income of residents in Chongqing reported by Municipal Bureau of Statistics in $2013^{[23]}$, the income of a participant was layered as four classes, with an income of over 728 US dollars (5000 Chinese yuan) assigned as " 3 ", $436 \sim 727$ US dollars (3000 4999 Chinese yuan) assigned as "2", $145 \sim 435$ US dollars (1000 2999 Chinese yuan) assigned as " 1 ", and less than 144 US dollars (1000 Chinese yuan) assigned as " 0 ". For the medical insurance types, the urban workers' basic medical insurance was defined as " 3 ", the urban residents' basic medical insurance was "2", the novel rural cooperative medical 
insurance was " 1 ", and the others (such as commercial medical insurance, etc.) were " 0 ". As Chinese people have a tradition of filial piety, we decided to include the number of offspring of the participants in the model which was also expressed numerically.

Need Factors The need factors refer to the demands of medical service made by family members which are the premise and direct influencing factors of medical service utilization, including self-health assessment, prevalence of chronic diseases, as well as disability ${ }^{[19]}$. In present study, the self-reported health status had 5 grades: very well (4), well (3), average (2), poor (1), and not at all (0). Previous studies reported that $58.3 \%$ of the elderly in China suffered from hypertension, $19.4 \%$ from diabetes, and $37.2 \%$ from

dyslipidemia ${ }^{[24]}$. Therefore, these three diseases were included in the model to indirectly evaluate the condition of chronic disease in participants. If no drugs were taken within 3 months, it would be determined as no and valued as " 1 ", otherwise the value would be "0". We applied activities of daily living (ADL) to evaluate whether the participants were disabled ${ }^{[25]}$. If participants had the ability to independently conduct six activities in their daily life, they were diagnosed as non-disabled, with a value of " 1 ". If more than one activity could not be done without help, we identified them as disabled, with a value of "0".

\subsection{Data analyses}

SPSS 22.0 software was used for data analyses, and quantitative data such as age were described statistically by mean and standard deviation ( $\overline{\mathrm{x}} \pm \mathrm{SD}$ ). Taking Anderson model as the analysis framework, the probability of the elderly in communities to receive the novel integrated care service was set to $\rho$, and the odds ratio (odds) was to $\rho / 1-\rho$. After logit transformation, the logarithmic odds ratio is set to [Due to technical limitations, this equation is only available as a download in the supplemental files section]. Using binary logistics regression model, the predisposing factors, enabling factors, and need factors were successively included in the model, and the influence differences of the three groups of factors were compared by three regression results. The three models are as follows:

[Due to technical limitations, this equation is only available as a download in the supplemental files section.]

In which, $\mathrm{N}=1180 \otimes \mathrm{x}_{1}=$ predisposing factors, $\mathrm{x}_{2}=$ enabling factors, $\mathrm{x}_{3}=$ need factors.

\section{Results}

\subsection{Demographic analysis}

URBMI = urban residents' basic medical insurance, $\mathrm{NCMI}$ = novel rural cooperative medical insurance, UEBMI = urban workers' basic medical insurance, $\mathrm{SD}=$ standard deviation

Table 1 showed that $68.73 \%$ participants $(N=811)$ were willing to accept the novel integrated care services. In terms of predisposing factors, the numbers of male $(\mathrm{N}=605)$ and female participants $(\mathrm{N}=575)$ were comparative with an average age 72.14 years old. According to the standard age grouping for the elderly ${ }^{[26]}$, most participants were still "mildly-old" (65-74 years old). As for the education level, most participants were poorly educated, and only $32.30 \%$ had completed the nine-year compulsory education in China, graduating from a middle school. In terms of marriage, $18.39 \%$ of the participants were currently in a "no spouse" condition. Regarding the residential areas, ordinary counties and autonomous counties were considered as a single area due to the relatively limited samples in both sites. However, the combined number of participants living in counties (27.54\%) was statistically less than that living in districts (72.46\%).

In terms of enabling factors, the income of the participants was in the middle class, and nearly half of the participants' annual income was between 436 and 727 dollars. In terms of medical insurance type, $60.68 \%$ of participants were enrolled in UEBMI. In addition, one child policy once was a basic policy in China. It advocated birth control and suggested a family to raise only one child. Therefore, most participants only had either a son $(1.08 \pm 0.88)$ or a daughter $(1.10 \pm 0.94)$.

In terms of need factors, most participants were optimistic about the self-assessment of their health conditions. Among the three diseases enrolled in the model, nearly half (45.93\%) of the participants had dyslipidemia-associated health issues and most (95.17\%) of the participants were able to take care of themselves without any disabilities. 


\subsection{Regression analysis of binary logistics}

We applied the predisposing factors, enabling factors, and need factors to the regression model successively and binary logistics regression analysis was utilized to examine the predictive factors for the acceptance of the novel integrated care service.

In Table 2, the results from strength test of the correlation between the independent variables and dependent variables showed that the Cox-snell square and nagelkerke square of the three models gradually increased, indicating that there was a moderate correlation between the independent variables and dependent variables in the three models ${ }^{[27]}$. We also performed Hosmer and Lemeshow Test; P value ( $(0.05)$ didn't reach a statistical significance. However, the overall regression model had a good fitness and the representative independent variables could effectively predict our dependent variables ${ }^{[28]}$. Meanwhile, the frequencies of the correct overall classification of the three models were $68.6 \%, 70.9 \%$, and $71.9 \%$, respectively which indicated that the model 3 had the best overall adaptability $(71.9 \%)$ followed by model 2 and model 1 , with an interpretation of $70.9 \%$ and $68.6 \%$, respectively $[27]$. It is very certain that the degree of interpretation changed more after the addition of enabling factors to model 1 compared with the addition of need factors to model 2. Therefore, we suggested that enabling factors had the greatest impact in this study; predisposing factors and need factors also had significant impact with the overall adaptability of Model 3 being the best.

Table 2 listed the regression coefficients, standard error, odds ratio, confidence interval for all independent variables. Firstly, only predisposing factors were investigated in model 1, including gender, age, education level, marital status, and residential region. Three variables (gender囚education level, and region) emerged as significant factors, among which males were more inclined to receive this novel integrated care service and females were only 0.76 time as many as men. In terms of the educational level, the higher the educational level was, the easier this pension service was provided. Referring to the residence, the elderly from counties received this service less than those from districts with a ratio of 0.65 : 1 . However, there was no significant relationship between marital status and acceptance of this service.

Secondly, four enabling factors (income, insurance type, the number of sons, and the number of daughters) were assessed in the model 2, three variables were insignificant but not insurance type whose OR value (0.44) of NCMI was the lowest compared with the reference parameter UENMI. There was no significant correlation between income or the number of children and the application of the service.

Thirdly, five need factors (self-reported health status, hypertension, diabetes, dyslipidemia and disability) were assessed in the model 3. Participants who rated their health conditions as "not at all" had the highest odd value of 4.03 which indicated that these participants were 4.03 times as many as those in "average". Considering the chronic diseases, we found that participants with diabetes and disabilities were more likely to seek for the services; interestingly, participants without hypertension and dyslipidemia were more likely to accept integrated care and pension services which were 1.94 times and 1.46 times higher than those with the diseases, respectively.

\section{Discussion}

This study attempted to analyze the accepting behaviors of elderly people in Chinese communities in the face of a novel integrated care service and employed a verified theoretical model to describe the relevant factors of the accepting behaviors in order to promote the utilization of medical and health services by elderly people in communities and develop primary health care institutions.

Overall, the explanatory powers of predisposing factors and need factors were stronger than that of enabling factors in the research of the influencing factors for the application of medical health services ${ }^{[29-31]}$. However, the application of the novel integrated care service was significantly explained by enabling factors rather than predisposing factors and needed factors. This is different from other studies using Anderson model. Possibly, this is related to our choice of dependent variables. In this study, we selected the novel integrated care service as the outcome model rather than general health services such as professional mental health care ${ }^{[32,}$

${ }^{33]}$, case management support services ${ }^{[16]}$, dental services ${ }^{[34]}$, or outpatient or inpatient services ${ }^{[30]}$. Medical Consortium is a relatively innovative concept for older adults. At present, this model is still experiencing continuous development and improvement. The elderly population still holds a conservative attitude towards it. In addition, financing factors are considered to serve as 
conditions allowing the seeking for services ${ }^{[18]}$, which implies that the elderly without financial concerns will be more free to choose medical services and make efforts to improve their health, while those encountering financial issues have fewer choices. Therefore, the two reasons may explain why the application of the novel integrated care service was significantly explained by enabling factors rather than predisposing factors and needed factors.

Here, we used model 3 to discuss the factors affecting elderly people's accepting behaviors for health care services in communities, odds ratios from binary logistics regression analysis for predisposing factors revealed that the education level was statistically significant. Namely, those who were highly educated were more willing to receive the services provided by Medical Consortium. This finding is consistent with past studies ${ }^{[35]}$. Potentially, older people with higher education degrees have more awareness of health management ${ }^{[36]}$ and can motivate themselves to promote and maintain their behaviors for healthy management, like making full use of preventive health services. This reminds us that primary health care institutions in communities should play an exclusive role in promoting the health literacy among aged people. What's more, they should encourage people to engage in healthenhancing activities based on the concept of ageing ${ }^{[37]}$.

At present, there are mainly three medical insurance plans in China: a. UEMI which was formally established in 1998; b. NCMI for rural residents formally established in 2003; and c. URMI for unemployed residents which was formally established in 2007. These social medical insurances had covered $95 \%$ residents in China by $2015^{[38]}$. In terms of enabling factors, elderly people in communities enrolled in NCMI had the least willingness to take health services. Our finding was consistent with a national survey within representative middle-aged and elderly households in China [39]. This may be due to the fact that the coverage of the novel rural cooperative medical system is far less than that of URBMI and UEBMI. Besides, the rural population has limited access to medical care and more economic burdens than urban residents ${ }^{[40]}$. This suggests that the government should focus on optimizing the allocation of medical insurance resources and unifying health care plans in the following policies.

Participants who claimed their health level as "not at all" were willing to receive integrated care service at most. This was observed in almost all the past studies ${ }^{[18,41]}$. Regarding the effect of chronic diseases on the health services, different diseases had inconsistent influence on people's choices of taking health care services which was identified by Peng's study of 1,056 disabled elderly people in China ${ }^{[42]}$. This result could be explained by the fact that our survey respondents might have other chronic diseases. And we only chose three diseases with the highest incidences in the older adults, i.e. hypertension, diabetes, and dyslipidemia. Some elderly people have been in a state of illness for many years. However, these aged people might not need medical services if they maintain a health management which turns out that chronic diseases such as hypertension have little impact on their daily life. With the aforementioned reasons, many elderly people take health services only when they have already had serious health issues.

As for the impact of disability on the acceptability of medical services, our results showed that disabled elderly people were less likely to receive medical health services, which was consistent to the results from $\mathrm{Kim}^{[30]}$. This may be explained by the traditional culture of filial piety in Asian countries. In a traditional Chinese family, parents are more inclined to go through their aged years by living with their children. In other words, the Chinese old people are more willing to receive long-term care services at home and emergency medical services will be only selected when adverse events or disease progression result in the hospitalization. Consistently, there are studies showing that Chinese aged people also have a low rate of psychological consultation ${ }^{[43]}$. Our study highlights the importance of the aforementioned traditional culture in accessing professional health services. In their role as gatekeepers to the medical system, families may contribute to efficient utilization of resources while reducing costs for hospital emergency departments.

\section{Strengths and limitations}

The strength of this study is to investigate the factors of the elderly in communities affecting a novel integrated care service in China. This service is experiencing development and maturation favored by governmental policies. Besides, our research was carried out under a verified theoretical framework which is of scientific value to some extent. However, there are still some limitations in this study. Firstly, this was a cross-sectional study that failed to gain insight into the causal relationship between potential determinants and the acceptability of health services; secondly, this acceptability was detected by a binary variable wherein participants only responded as "yes" or "no" instead of the frequency or intensity of services; thirdly, the variables in our 
model may not be able to cover all the important potential factors. For example, ethnic and religious beliefs were not discussed here. Thus, we plan to expand the sample size and include more variables to analyze the causal relationship in Anderson's health service utilization models in the sense of pre-disposing factors, enabling factors, and need factors in our future studies.

\section{Conclusion}

The results of this study indicate that about $68.73 \%$ of the community-dwelling elderly need the novel integrated care services. In this study, enabling factors have been shown to contribute to the acceptance most significantly in the model 3 with the best explanatory power. First, regarding predisposing factors, participants were more likely to have the utilization of integrated care services if they had a high degree of education. Second, for enabling factors, participants having urban residents' basic medical insurance received less novel health services. Third, in terms of need factors, health care acceptance was closely related to participants' self-rated health status, chronic diseases and disability. In conclusion, Chinese government should allocate resources rationally and unify the medical insurance plans; and a home care-dominated, community care-supplemented and hospital careguided geriatric care system should be established in China.

\section{List Of Abbreviations}

BMHSU: standard deviation

SD: standard deviation

ADL: activities of daily living

URBMI: urban residents' basic medical insurance,

NCMI: novel rural cooperative medical insurance

UEBMI: urban workers' basic medical insurance

SE: standard error,

OR: odds ratio

$\mathrm{Cl}$ : confidence interval

\section{Declarations}

\section{Ethics approval and consent to participate}

This study was conducted according to the recommendations of the Declaration of Helsinki and was approved by the institutional review boards of the First Affiliated Hospital of Chongqing Medical University (No.:2019-105), Chongqing, China. Written consent was obtained from all participants.

\section{Consent for publication}

Not applicable.

\section{Availability of data and materials}

Part of the datasets generated during the current study are publicly available in the National Bureau of Statistics of China and Municipal Bureau of Statistics of Chongqing respectively, [http://data.stats.gov.cn], [http://www.cqdata.gov.cn]. Other datasets used during the current study are only available from the corresponding author on reasonable request. 


\section{Competing interests}

The authors declare that they have no competing interests.

\section{Funding}

This work was supported by Chongqing Science and Technology Committee (No.: catc2018jscx-mszdX0013). The funding agencies had no role in design, analysis, interpretation, or writing of this study.

\section{Authors' contributions}

$\mathrm{HHH}$ participated in the design of the study and analyzed the data, and wrote the first draft of this manuscript. CZY participated in statistical analysis and the interpretation of results. CM and JWB participated in the training of research assistants and collection of questionnaires. XL designed the study and supervised all the stages of the study up to the report writing. XMZ and ZQH participated in the design, the statistical analysis, and the coordination of the study. All authors read and approved the final manuscript.

\section{Acknowledgements}

The authors gratefully acknowledge the generous, constructive remarks of the anonymous peer reviewers. In addition, Huang Huanhuan especially wishes to thank her friends, Li Taoyi, Guan Yaxin, Che Xuan, He Jia, Dong Hong, and her teachers Li Feng $\rrbracket$ Qian Fenghua who provided powerful support during the research.

\section{References}

[1]NATIONAL BUREAU OF STATISTICS OF CHINA. http://data.stats.gov.cn. Accessed 20 August 2019.

[2]FANG E F, SCHEIBYE-KNUDSEN M, JAHN H J, et al. A research agenda for aging in China in the 21st century [J]. Ageing Research Reviews, 2015, 24(Pt B): 197-205.

[3]THE L. Ageing in China: a ticking bomb [J]. Lancet (London, England), 2016, 388(10056): 2058.

[4]HATANO Y, MATSUMOTO M, OKITA M, et al. The Vanguard of Community-based Integrated Care in Japan: The Effect of a Rural Town on National Policy [J]. International journal of integrated care, 2017, 17(2): 2.

[5]YIP W, HSIAO W. Harnessing the privatisation of China's fragmented health-care delivery [J]. Lancet (London, England), 2014, 384(9945): 805-18.

[6]XU J, PAN R, PONG R W, et al. Different Models of Hospital-Community Health Centre Collaboration in Selected Cities in China: A Cross-Sectional Comparative Study [J]. International journal of integrated care, 2016, 16(1): 8.

[7]CAI M, LIU E, TAO H, et al. Does A Medical Consortium Influence Health Outcomes of Hospitalized Cancer Patients? An Integrated Care Model in Shanxi, China [J]. International journal of integrated care, 2018, 18(2): 7.

[8]GAO F. To promote the high quality nursing resources to grass roots in the construction of regional medical consortium [J]. Chinese Nursing Management, 2017, 17(05): 577-9.

[9]General Office of the State Council, The People's Republic of China. Guiding opinions of the general office of the state council on promoting the construction and development of Medical Consortium. Available from: http://www.gov.cn/xinwen/201704/26/content_5189089.htm.

[10] TAO W, LI J, WEN J, et al. A brief introduction of evaluation for medical consortium in China and abroad [J]. CHINESE JOURNAL OF EVIDENCE-BASED MEDICINE, 2019, 19(03): 368-72. 
[11] DOU L, LIU X, ZHANG T, et al. Health care utilization in older people with cardiovascular disease in China [J]. Int J Equity Health, $2015,14(59$.

[12] HU C, YU W, LV Y, et al. Study on the Health Status and Health Service Utilization of the Elderly of a Remote and Poor Village in a Mountainous Area in Jinzhai, Anhui [J]. International journal of environmental research and public health, 2017, 14(4):

[13] FU X, SUN N, XU F, et al. Influencing factors of inequity in health services utilization among the elderly in China [J]. Int J Equity Health, 2018, 17(1): 144 .

[14] ANDERSEN R. A behavioral model of families' use of health services [J]. Journal of Human Resources, 1968, 7(1): 125.

[15] ANDERSEN R M. National health surveys and the behavioral model of health services use [J]. Medical care, 2008, 46(7): 64753.

[16] BAPTISTE B, DAWSON D R, STREINER D. Predicting use of case management support services for adolescents and adults living in community following brain injury: A longitudinal Canadian database study with implications for life care planning [J]. NeuroRehabilitation, 2015, 36(3): 301-12.

[17] DE JESUS M, XIAO C. Cross-border health care utilization among the Hispanic population in the United States: implications for closing the health care access gap [J]. Ethnicity \& health, 2013, 18(3): 297-314.

[18] BABITSCH B, GOHL D, LENGERKE T V. Re-Revisiting Andersen's Behavioral Model of Health Services Use: A Systematic Review of Studies from 1998-2011 [J]. GMS Psycho-Social-Medicine, 2012, 9(Doc11.

[19] ANDERSEN R M. Revisiting the behavioral model and access to medical care: does it matter? [J]. Journal of health and social behavior, 1995, 36(1): 1-10.

[20] HA W, LUO Y, LÜ L. The Chinese Experience in the Universalization of Compulsory Education: 1978-2018 [J]. Journal of Nanjing Normal University(Social Science Edition), 2018, 06): 31-9.

[21] ZENG X, WANG L, YIN P, et al. Subnational analysis of healthcare access and quality in China during 1990-2015 [J]. Chinese Science Bulletin, 2018, 63(25): 2631-40.

[22] INDICATORS C, ANDERSEN R M, DAVIDSON P L. IMPROVING ACCESS TO CARE IN AMERICA [J]. 2007,

[23] MUNICIPAL BUREAU OF STATISTICS OF CHONGQING. http://www.cqdata.gov.cn. Accessed 20 August 2019

[24] WANG L, CHEN Z, ZHANG M, et al. A survey on the prevalence and burden of chronic diseases among the elderly in China [J]. Chinese journal of epidemiology, 2019, 40(3): 277-83.

[25] CHEN S, QIN J, LI Y, et al. Disability and Its Influencing Factors among the Elderly in a County, Guangxi Province, China [J]. International journal of environmental research and public health, 2018, 15(9):

[26] NEUGARTEN B L, NEUGARTEN D A. The Meanings of Age: Selected Papers [M]. 1996.

[27] FIDELL L S. Using multivariate statistics, 6th Edition [J]. 2012,

[28] HOSMER D W, LEMESHOW S. Assessing the Fit of the Model [M]. 1989.

[29] SHAO S, WANG M, JIN G, et al. Analysis of health service utilization of migrants in Beijing using Anderson health service utilization model [J]. Bmc Health Services Research, 2018, 18(1): 462.

[30] HAN-KYOUL K, MUNJAE L. Factors associated with health services utilization between the years 2010 and 2012 in Korea: using Andersen's Behavioral model [J]. Osong Public Health \& Research Perspectives, 2016, 7(1): 18-25. 
[31] BAYUO J. Experiences with out-patient hospital service utilisation among older persons in the Asante Akyem North DistrictGhana [J]. BMC Health Serv Res, 2017, 17(1): 652.

[32] ROSALES R, CALVO R. "Si Dios Quiere": Fatalismo and use of mental health services among Latinos with a history of depression [J]. Social work in health care, 2017, 56(8): 748-64.

[33] HAN K M, WON E, PAIK J W, et al. Mental health service use in adults with suicidal ideation within a nationally representative sample of the Korean population [J]. Journal of affective disorders, 2016, 193(339-47.

[34] PILGER C, MENON M U, MATHIAS T A. [Health services use among elderly people living in the community] [J]. Revista da Escola de Enfermagem da U S P, 2013, 47(1): 213-20.

[35] ARAUJO M E A, SILVA M T. Prevalence of health services usage and associated factors in the Amazon region of Brazil: a population-based cross-sectional study [J]. 2017, 7(11): e017966.

[36] ALMEIDA A, NUNES B P, DURO S M S, et al. Socioeconomic determinants of access to health services among older adults: a systematic review [J]. Revista de saude publica, 2017, 51(50.

[37] KALACHE A, GATTI A. Active ageing: a policy framework [J]. Advances in gerontology = Uspekhi gerontologii, 2003, 11(7-18.

[38] COMMISSION N H A F P. 9th global conference on health promotion China: National Health and Family Planning Commission.

[39] WANG Z, LI X, CHEN M, et al. Social health insurance, healthcare utilization, and costs in middle-aged and elderly communitydwelling adults in China [J]. International Journal for Equity in Health, 2018, 17(1): 17.

[40] MENG Q, FANG H, LIU X, et al. Consolidating the social health insurance schemes in China: towards an equitable and efficient health system [J]. Lancet (London, England), 2015, 386(10002): 1484-92.

[41] PALLADINO R, TAYU LEE J, ASHWORTH M, et al. Associations between multimorbidity, healthcare utilisation and health status: evidence from 16 European countries [J]. Age and ageing, 2016, 45(3): 431-5.

[42] XIZHE P, LIANGJUN S, JIANKUN H. Determinants of Long-Term Care Services among Disabled Older Adults in China: A Quantitative Study based on Andersen's Behavioral Model [J]. Population Research, 2017, 41(04): 46-59.

[43] GUO C, LI N, CHEN G, et al. Mental health service utilization and its associated social factors among elderly people with a mental disability in China: A national population-based survey [J]. Scandinavian journal of public health, 2019, 47(2): 215-20.

\section{Tables}

Table 1 Characteristics of Variables

Table 2 Logistic regression analysis predicting likelihood of utilizing the novel integrated care services among community-dwelling elderly

$* P \unlhd 0.1, * * \mathrm{P} \sqcap 0.05$. $\mathrm{SE}=$ standard error, $\mathrm{OR}=$ odds ratio; $\mathrm{CI}=$ confidence interval

\section{Figures}




\begin{tabular}{|c|c|c|c|c|}
\hline Variables & & Definition & Statistics $(\mathrm{N}=1180)$ & percentage(\%) \\
\hline \multirow{2}{*}{ Dependent Variables } & Services utilization & $1=$ no & 369 & $31.27 \%$ \\
\hline & & $0=$ yes & 811 & $68.73 \%$ \\
\hline \multirow[t]{12}{*}{ Predisposing Factors } & Gender & $1=$ Male & 605 & $51.27 \%$ \\
\hline & & $0=$ Female & 575 & $48.73 \%$ \\
\hline & Age & Mean (SD) & 72.14 & 8.72 \\
\hline & Education level & $4=$ Illiteracy & 76 & $6.44 \%$ \\
\hline & & $3=$ Elementary school & 297 & $25.17 \%$ \\
\hline & & $2=$ Middle school & 427 & $36.19 \%$ \\
\hline & & $1=$ High school & 221 & $18.73 \%$ \\
\hline & & $0=$ Over college & 159 & $13.47 \%$ \\
\hline & Marital & $1=$ no Spouse & 217 & $18.39 \%$ \\
\hline & & $0=$ Spouse & 963 & $81.61 \%$ \\
\hline & Region & $1=$ Country & 325 & $27.54 \%$ \\
\hline & & $0=$ District & 855 & $72.46 \%$ \\
\hline \multirow[t]{10}{*}{ Enabling Factors } & Household income & $3=$ More than 727 & 112 & $9.49 \%$ \\
\hline & & $2=$ Less than 727 & 550 & $46.61 \%$ \\
\hline & & $1=$ Less than 436 & 381 & $32.29 \%$ \\
\hline & & $0=$ Less than 145 & 137 & $11.61 \%$ \\
\hline & Insurance type & 3=UEBMI & 716 & $60.68 \%$ \\
\hline & & $2=\mathrm{URBHI}$ & 281 & $23.81 \%$ \\
\hline & & $1=$ NRCMS & 128 & $10.85 \%$ \\
\hline & & $0=$ Others & 55 & $4.66 \%$ \\
\hline & Son & Mean (SD) & 1.08 & 0.88 \\
\hline & Daughter & Mean (SD) & 1.13 & 0.94 \\
\hline \multirow[t]{13}{*}{ Need Factors } & Self-reported & $4=$ Very Well & 231 & $19.58 \%$ \\
\hline & health status & $3=$ Well & 383 & $32.46 \%$ \\
\hline & & $2=$ Average & 431 & $36.53 \%$ \\
\hline & & $1=$ poor & 115 & $9.75 \%$ \\
\hline & & $0=$ Not at all & 20 & $1.69 \%$ \\
\hline & Hypertension & $1=$ no & 638 & $54.07 \%$ \\
\hline & & $0=$ yes & 542 & $45.93 \%$ \\
\hline & Diabetes & $1=$ no & 929 & $78.73 \%$ \\
\hline & & $0=$ yes & 251 & $21.27 \%$ \\
\hline & Dyslipidemia & $1=$ no & 937 & $79.41 \%$ \\
\hline & & $0=$ yes & 243 & $20.59 \%$ \\
\hline & Disability & $1=$ no & 1123 & $95.17 \%$ \\
\hline & & $0=$ yes & 57 & $4.83 \%$ \\
\hline
\end{tabular}




\begin{tabular}{|c|c|c|c|c|c|c|c|c|c|c|c|c|c|}
\hline \multirow[t]{2}{*}{ Variables } & & \multicolumn{4}{|l|}{ Model 1} & \multicolumn{4}{|l|}{ Model 2} & \multicolumn{4}{|l|}{ Model 3} \\
\hline & & B & $\mathrm{SE}$ & OR & $95 \%$ CI & B & SE & OR & $95 \%$ CI & B & $\mathrm{SE}$ & OR & $95 \%$ CI \\
\hline Gender (Male) & Female & $-0.27 * *$ & 0.13 & 0.76 & $\begin{array}{l}0.59- \\
1.00\end{array}$ & $-0.24^{*}$ & 0.14 & 0.78 & $\begin{array}{l}0.60- \\
1.03\end{array}$ & -0.23 & 0.14 & 0.79 & $\begin{array}{l}0.60- \\
1.05\end{array}$ \\
\hline Age & & 0.00 & 0.01 & 1.00 & $\begin{array}{l}0.99- \\
1.02\end{array}$ & 0.00 & 0.01 & 1.00 & $\begin{array}{l}0.98- \\
1.01\end{array}$ & 0.00 & 0.01 & 1.00 & $\begin{array}{l}0.98- \\
1.01\end{array}$ \\
\hline $\begin{array}{l}\text { Education } \\
\text { (Illiteracy) }\end{array}$ & $\begin{array}{l}\text { Elementary } \\
\text { school }\end{array}$ & 0.38 & 0.26 & 1.47 & $\begin{array}{l}0.87- \\
2.46\end{array}$ & 0.23 & 0.28 & 1.26 & $\begin{array}{l}0.73- \\
2.17\end{array}$ & 0.28 & 0.28 & 1.32 & $\begin{array}{l}0.76- \\
2.30\end{array}$ \\
\hline & $\begin{array}{l}\text { Middle } \\
\text { school }\end{array}$ & $0.53^{* *}$ & 0.26 & 1.69 & $\begin{array}{l}1.02- \\
2.82\end{array}$ & 0.24 & 0.29 & 1.27 & $\begin{array}{l}0.72- \\
2.24\end{array}$ & 0.34 & 0.29 & 1.41 & $\begin{array}{l}0.76- \\
2.30\end{array}$ \\
\hline & $\begin{array}{l}\text { High } \\
\text { school }\end{array}$ & $1.33^{* *}$ & 0.3 & 3.78 & $\begin{array}{l}2.10- \\
6.82\end{array}$ & $1.04^{* *}$ & 0.33 & 2.83 & $\begin{array}{l}1.47- \\
5.43\end{array}$ & $1.15^{* *}$ & 0.34 & 3.16 & $\begin{array}{l}1.63- \\
6.15\end{array}$ \\
\hline & $\begin{array}{l}\text { Over } \\
\text { college }\end{array}$ & $1.41^{* *}$ & 0.33 & 4.08 & $\begin{array}{l}2.15- \\
7.76\end{array}$ & $1.19 * *$ & 0.38 & 3.30 & $\begin{array}{l}1.57- \\
6.92\end{array}$ & $1.26^{* *}$ & 0.39 & 3.54 & $\begin{array}{l}1.66- \\
7.53\end{array}$ \\
\hline $\begin{array}{l}\text { Marriage (no } \\
\text { Spouse) }\end{array}$ & Spouse & -0.07 & 0.17 & 0.93 & $\begin{array}{l}0.66- \\
1.32\end{array}$ & -0.08 & 0.18 & 0.92 & $\begin{array}{l}0.65- \\
1.31\end{array}$ & -0.13 & 0.19 & 0.88 & $\begin{array}{l}0.61- \\
1.27\end{array}$ \\
\hline $\begin{array}{l}\text { District } \\
\text { (Country) }\end{array}$ & District & $-0.43 * *$ & 0.15 & 0.65 & $\begin{array}{l}0.49- \\
0.87\end{array}$ & $-0.27^{*}$ & 0.16 & 0.76 & $\begin{array}{l}0.56- \\
1.04\end{array}$ & -0.24 & 0.16 & 0.78 & $\begin{array}{l}0.57- \\
1.08\end{array}$ \\
\hline $\begin{array}{ll}\text { Income } & \text { (More } \\
\text { than 727) } & \end{array}$ & $\begin{array}{l}\text { less than } \\
145\end{array}$ & & & & & -0.32 & 0.36 & 0.72 & $\begin{array}{l}0.83- \\
2.74\end{array}$ & -0.36 & 0.37 & 0.70 & $\begin{array}{l}0.34- \\
1.46\end{array}$ \\
\hline & $\begin{array}{l}\text { less than } \\
436\end{array}$ & & & & & 0.41 & 0.30 & 1.50 & $\begin{array}{l}0.69- \\
2.06\end{array}$ & 0.40 & 0.31 & 1.48 & $\begin{array}{l}0.80- \\
2.74\end{array}$ \\
\hline & $\begin{array}{l}\text { less than } \\
727\end{array}$ & & & & & 0.17 & 0.28 & 1.19 & $\begin{array}{l}0.68- \\
1.33\end{array}$ & 0.16 & 0.29 & 1.17 & $\begin{array}{l}0.67- \\
2.07\end{array}$ \\
\hline $\begin{array}{l}\text { Insurance type } \\
\text { (UENMI) }\end{array}$ & URBMI & & & & & -0.05 & 0.17 & 0.96 & $\begin{array}{l}0.27- \\
0.73\end{array}$ & 0.01 & 0.17 & 1.01 & $\begin{array}{l}0.72- \\
1.42\end{array}$ \\
\hline & NCMI & & & & & $-0.81 * *$ & 0.25 & 0.44 & $\begin{array}{l}0.77- \\
2.99\end{array}$ & $-0.78^{* *}$ & 0.25 & 0.46 & $\begin{array}{l}0.28- \\
0.76\end{array}$ \\
\hline & others & & & & & 0.41 & 0.35 & 1.51 & $\begin{array}{l}0.89- \\
1.25\end{array}$ & 0.41 & 0.36 & 1.51 & $\begin{array}{l}0.75- \\
3.05\end{array}$ \\
\hline Son & & & & & & 0.05 & 0.08 & 1.05 & $\begin{array}{l}0.87- \\
1.17\end{array}$ & 0.04 & 0.09 & 1.04 & $\begin{array}{l}0.88- \\
1.23\end{array}$ \\
\hline Daughter & & & & & & 0.00 & 0.08 & 1.00 & $\begin{array}{l}0.60- \\
1.03\end{array}$ & 0.01 & 0.08 & 1.01 & $\begin{array}{l}0.87- \\
1.17\end{array}$ \\
\hline $\begin{array}{l}\text { Self-reported } \\
\text { health status } \\
\text { (Average) }\end{array}$ & not at all & & & & & & & & & $1.39 *$ & 0.78 & 4.03 & $\begin{array}{l}0.88- \\
18.46\end{array}$ \\
\hline & poor & & & & & & & & & 0.16 & 0.24 & 1.17 & $\begin{array}{l}0.73- \\
1.89\end{array}$ \\
\hline & well & & & & & & & & & 0.20 & 0.16 & 1.22 & $\begin{array}{l}0.89- \\
1.67\end{array}$ \\
\hline & very well & & & & & & & & & $0.66^{* *}$ & 0.21 & 1.94 & $\begin{array}{l}1.29- \\
2.92\end{array}$ \\
\hline $\begin{array}{l}\text { Hypertension } \\
\text { (no) }\end{array}$ & yes & & & & & & & & & $-0.51 * *$ & 0.16 & 0.60 & $\begin{array}{l}0.44- \\
0.82\end{array}$ \\
\hline Diabetes (no) & yes & & & & & & & & & $0.38^{* *}$ & 0.17 & 1.46 & $\begin{array}{l}1.05- \\
2.03\end{array}$ \\
\hline Dyslipidemia (no) & yes & & & & & & & & & $0.56^{* *}$ & 0.18 & 1.76 & $\begin{array}{l}1.23- \\
2.51\end{array}$ \\
\hline Disability (no) & yes & & & & & & & & & $-0.96 * *$ & 0.42 & 0.38 & $\begin{array}{l}0.17- \\
0.87\end{array}$ \\
\hline $\begin{array}{l}\text { Cox \& Snell R } \\
\text { Square }\end{array}$ & & 0.060 & & & & 0.090 & & & & 0.122 & & & \\
\hline $\begin{array}{l}\text { Nagelkerke } \quad \mathrm{R} \\
\text { Square }\end{array}$ & & 0.085 & & & & 0.126 & & & & 0.172 & & & \\
\hline $\begin{array}{l}\text { Hosmer and } \\
\text { Lemeshow Test }\end{array}$ & & & & & & & & & & & & & \\
\hline Chi-square & & 10.218 & & & & 9.492 & & & & 9.272 & & & \\
\hline $\mathrm{df}$ & & 8 & & & & 8 & & & & 8 & & & \\
\hline$p$ & & 0.250 & & & & 0.303 & & & & 0.320 & & & \\
\hline
\end{tabular}




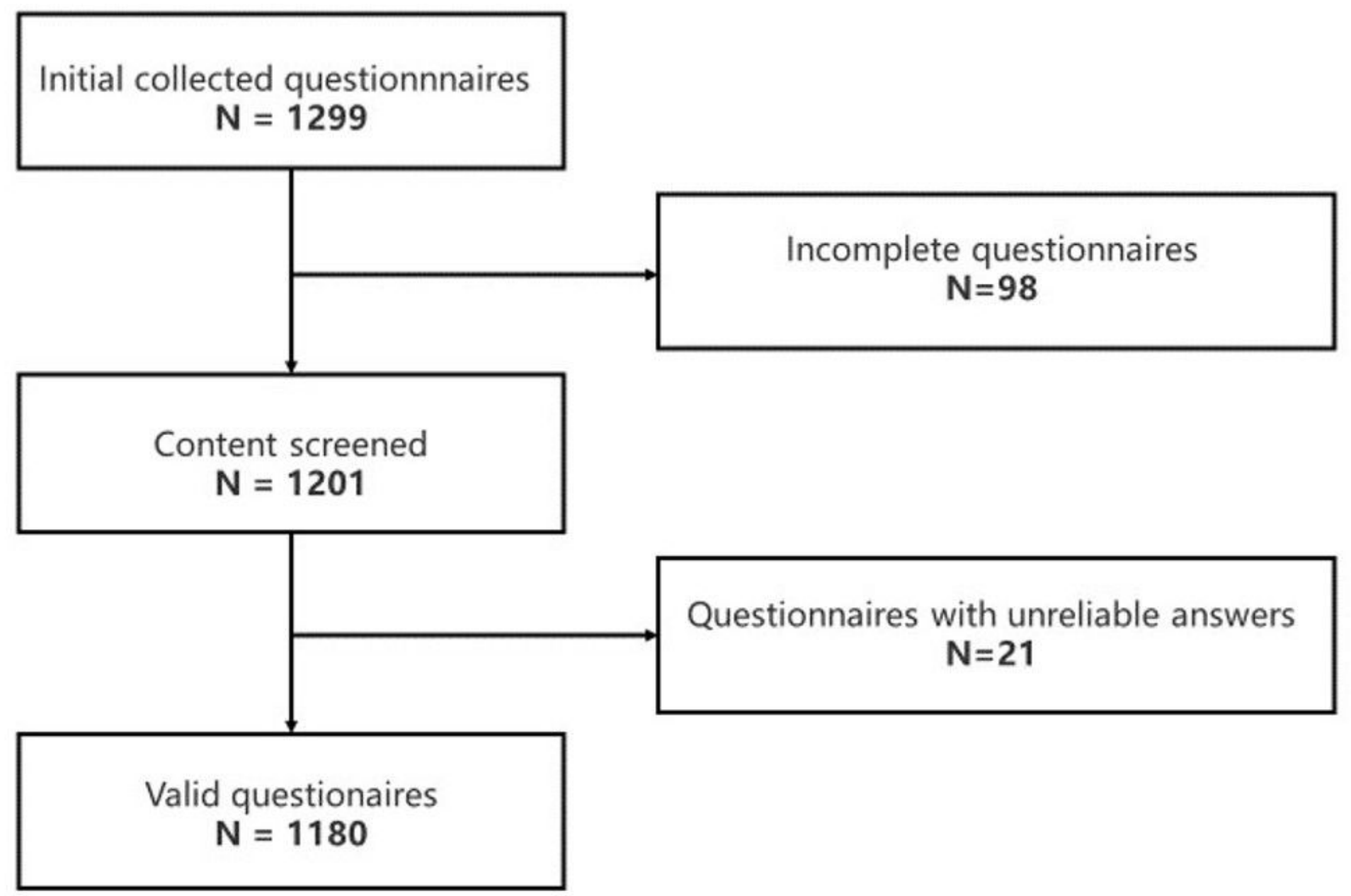

Figure 1

Flow chart of participant recruitment

\section{Supplementary Files}

This is a list of supplementary files associated with this preprint. Click to download.

- eq1.jpg

- eq2.jpg

- STROBEchecklistcrosssectional.docx 